\title{
VANTAGENS COMPARATIVAS REVELADAS E ORIENTAÇÃO REGIONAL DAS EXPORTAÇÕES AGRÍCOLAS BRASILEIRAS PARA A UNIÃOO EUROPÉIA ${ }^{1}$
}

\author{
Paulo D. Waquil \\ Augusto M. Alvim ${ }^{3}$ \\ Leonardo X. Silva ${ }^{4}$ \\ Glaucilene P. Trapp ${ }^{5}$
}

Resumo - Este artigo visou analisar o comportamento do comércio agrícola brasileiro com a União Européia (UE), em face das negociações para um acordo comercial entre o Mercosul e a UE. Foram calculados os índices de vantagens comparativas reveladas (VCR) e de orientação regional (IOR), no período de 1991 a 2001, cujos produtos relacionados foram soja e derivados, suco de laranja, fumo, frango, carne bovina, açúcar e café. Em conjunto, esses produtos tiveram, no período assinalado, participação superior a $20 \%$ no total das exportações do Brasil, tendo a soja e derivados, o suco de laranja e o café maior participação nas exportações mundiais. À exceção do açúcar, todos os produtos estudados tiveram a UE como importante destino das exportações. Os resultados do VCR expressam, em todos os produtos, maiores vantagens comparativas do Brasil, com valores estáveis ou crescentes ao longo da década. O IOR, por sua vez, ilustra a elevada orientação das exportações brasileiras para a UE, exceto para frango e açúcar, mas que, em geral, não aumentaram no período. Em conseqüência, um acordo entre os blocos, reduzindo ou eliminando barreiras tarifárias e não-tarifárias, poderá resultar em criação de comércio, favorecendo as exportações agrícolas brasileiras com destino à UE.

Palavras-chave: integração regional, comércio internacional, vantagens comparativas, agricultura.

\footnotetext{
${ }^{1}$ Recebido em 12/04/2004. Aceito em 30/04/2004.

${ }^{2}$ Doutor em Economia Agrícola. Professor do Departamento de Economia (DECON) e dos Programas de PósGraduação em Desenvolvimento Rural (PGDR) e Agronegócios (PPGAN) da UFRGS. End.: IEPE/UFRGS Av. João Pessoa, 31 - Porto Alegre, RS CEP 90040-000. E-mail: waquil@ufrgs.br.

${ }^{3}$ Doutor em Economia. Professor da Universidade de Santa Cruz do Sul (UNISC).

${ }^{4}$ Doutor em Economia. Professor da Pontifícia Universidade Católica do Rio Grande do Sul (PUCRS).

${ }^{5}$ Mestra em Desenvolvimento Rural. Consultora do Programa RS-Rural da Secretaria da Agricultura e Abastecimento do Estado do Rio Grande do Sul e Professora da Universidade de Santa Cruz do Sul (UNISC).
} 


\section{Introdução}

Ao longo da última década, a União Européia (UE) vem se consolidando como uma das principais regiões de destino dos produtos exportados pelo Mercado Comum do Sul (Mercosul) e de origem dos produtos importados pelo bloco, assim como uma importante fonte de investimentos realizados no Cone Sul. A maior parte das exportações do Mercosul para a UE tem sido de produtos agrícolas como, oleaginosas, carnes, suco de laranja, fumo e café. No entanto, as importações dos países do Mercosul originárias da UE incluem, principalmente, produtos de maior valor agregado destinados ao consumidor final. Como resultado do comércio entre essas regiões, o Mercosul apresenta saldo positivo, mesmo quando se consideram os fluxos totais, mas, sobretudo, quando se consideram apenas os fluxos de produtos agrícolas. As principais causas dessa maior afinidade comercial entre os países do Mercosul e a UE são as semelhanças entre as preferências dos consumidores e a complementaridade existente na produção. Segundo Bureau (2002), há poucas regiões no mundo que apresentam preferências dos consumidores tão similares como os países do Mercosul e da UE. Essa semelhança se deve, em parte, aos valores culturais e religiosos e aos hábitos de consumo difundidos pelos imigrantes europeus nos países da América Latina.

Existem, entretanto, pelo menos três fatores relacionados com complementaridade na produção que fortalecem o comércio entre o Mercosul e a EU, na atualidade. O primeiro deles está relacionado com as diferenças climáticas entre essas regiões, as quais resultam em produtos diferenciados, a exemplo dos produtos tropicais e subtropicais do Mercosul que complementam os de clima temperado da UE na composição das cestas de consumo. O segundo lugar está relacionado com a diferença, em termos de sazonalidade, da produção entre ambas as regiões, ou seja, quando é safra no hemisfério sul, é entressafra no hemisfério norte e vice-versa. $\mathrm{O}$ terceiro fator está relacionado com a disponibilidade e com o uso dos fatores de produção, que determinam como são alocados esses fatores e, por conseqüência, como se dá a especialização 
na produção. Como resultado dessa variável, os países do Mercosul apresentam, em geral, maior vantagem em produtos agrícolas de baixo valor agregado, enquanto os países da UE são mais especializados na produção de produtos de maior valor agregado (Bureau, 2002).

Formalmente, a então Comunidade Econômica Européia (CEE) firmou acordo de cooperação com os países do Mercosul em dezembro de 1995, com o objetivo de estabelecer uma associação inter-regional, aprofundando as relações política, econômica, financeira, social e cultural, com vistas a alcançar um tratado de livre comércio (Bulmer-Thomas, 2001). Especificamente a respeito do setor agrícola, a agenda de cooperação entre os dois blocos inclui a promoção do comércio de produtos agrícolas, a compatibilização da legislação para prevenir a formação de barreiras comerciais, a implementação de medidas de caráter ambiental, a proteção dos consumidores e a garantia da segurança alimentar. No entanto, apesar da existência de vários fatores que fortalecem o comércio entre a UE e o Mercosul, existem dificuldades nas negociações que envolvem maior acesso aos mercados, principalmente com relação ao setor agrícola. Entre os principais pontos conflitantes nas negociações agrícolas, salientam-se os subsídios concedidos aos produtores europeus, as barreiras tarifárias que são pontualmente elevadas em determinados produtos agrícolas considerados frágeis e as barreiras não-tarifárias de caráter técnico, sanitário e, ou, administrativo nos países da UE.

Associada a esses aspectos que dificultam a expansão do comércio entre os países do Mercosul e UE está a ampliação da UE rumo à Europa Central e Oriental, que acrescentará 10 novos países ao bloco ${ }^{6}$, os quais, em sua maioria, possuem a atividade primária como ponto central de suas economias. Nesse aspecto, a inclusão dos novos países naquele bloco e a conseqüente extensão do tratamento preferencial na região poderão constituir um novo entrave à expansão do comércio entre os países do Mercosul e da UE. Contudo, esse processo deverá enfrentar uma série de dificuldades, relacionadas com os custos de estender os

\footnotetext{
${ }^{6}$ Os 10 países já em processo de incorporação à UE são: Chipre, Eslováquia, Eslovênia, Estônia, Hungria, Letônia, Lituânia, Malta, Polônia e República Tcheca.
} 
benefícios da Política Agrícola Comum (PAC) àqueles novos membros.

Nesse contexto, este artigo visou analisar o comportamento do comércio dos principais produtos agrícolas entre os dois blocos (Mercosul e UE) ao longo da última década (1991 a 2001). Para isso, utilizaram-se dois índices para medir a eficiência produtiva e comercial no contexto das transformações nas relações internacionais, observando os efeitos regionais. O primeiro deles representa as Vantagens Comparativas Reveladas, mostrando se determinado país possui vantagens comparativas ao comparar seu peso dentro da pauta desse mesmo país com a mundial. $\mathrm{O}$ segundo é o Índice de Orientação Regional das exportações, que avalia a tendência de exportar o produto a países membros e não-membros.

Para atingir o objetivo proposto, inicialmente foram caracterizados os padrões comerciais, salientando-se a importância da agricultura na balança comercial e a participação de cada produto nas exportações brasileiras. A seguir, foram apresentados os cálculos dos índices de Vantagens Comparativas Reveladas e de Orientação Regional e para os seguintes agregados de produtos: soja e derivados, suco de laranja, fumo, frango, carne bovina, açúcar e café. No final, exibiram-se os resultados, as principais barreiras aplicadas pela UE e as conclusões.

\section{Caracterizaçãoe importância das exportações agrícolas brasileiras}

Ao longo da década de 1990, o setor agrícola brasileiro passou por um processo de intensa reformulação devido, entre outros fatores, à abertura comercial e ao aprofundamento das relações comerciais entre os países que compõem o Mercosul. Esse processo de abertura comercial esteve associado a um contexto adverso de queda nos preços dos produtos agrícolas, elevadas taxas de juros, valorização cambial e manutenção dos subsídios agrícolas por parte dos países desenvolvidos. Essa década foi também marcada por sucessivas negociações de livre comércio de âmbito multilateral, culminando com o encerramento da Rodada Uruguai do General Agreement for Trade and Tariffs (GATT) em 1994, que 
inclui o Acordo Agrícola, e com a criação da Organização Mundial do Comércio (OMC), a partir de 1995. No entanto, essas negociações pouco avançaram para a melhoria do acesso a mercados e redução de subsídios dos produtos agrícolas. Ao contrário, nos últimos anos vêm-se observando a manutenção e até mesmo um fortalecimento de posições protecionistas, principalmente por parte dos países desenvolvidos.

Apesar dessas mudanças, a agricultura brasileira manteve a sua importância como setor produtivo e exportador, dando grande contribuição para a balança comercial do país. Ao longo da década de 1990, mais de um terço das exportações brasileiras correspondia a produtos do setor agroindustrial. Sete dos principais produtos que compunham, em média, $23,6 \%$ do total das exportações brasileiras, na última década, foram então escolhidos para fazer parte deste estudo. São eles: soja e derivados (grão, farelo e óleo), suco de laranja (concentrado e não-concentrado), fumo (folhas e manufaturados), frango (in natura - inteiro ou em pedaços - e industrializado), carne bovina (refrigerada, congelada e industrializada), açúcar (bruto e refinado) e café (grão, torrado e solúvel).

De maneira geral, esses produtos apresentam distribuição estável na pauta de exportações brasileiras, apesar de todas as mudanças políticas e econômicas observadas ao longo da década de 1990. Em 2001, a soja e o açúcar representaram os produtos mais relevantes na pauta de exportações agrícolas, conforme apresentado na Tabela 1. É interessante também verificar que alguns desses produtos apresentam tendência de aumento da participação no total das exportações, como é o caso da soja, frango, carne bovina e açúcar, em vista do dinamismo desses segmentos. Em valores absolutos, a soma dos sete agregados de produtos passou de US\$ 6,5 bilhões em 1991 para US\$ 13,1 bilhões em 2001, de um total exportado pelo país equivalente a US\$ 58,2 bilhões nesse ano. 
Tabela 1 - Participação dos principais produtos agrícolas na pauta de exportações brasileiras (\%), 1991-2001

\begin{tabular}{lcccccccc}
\hline Ano & $\begin{array}{c}\text { Soja e } \\
\text { derivados }\end{array}$ & $\begin{array}{c}\text { Suco de } \\
\text { laranja }\end{array}$ & Fumo Frango & $\begin{array}{c}\text { Carne } \\
\text { Bovina }\end{array}$ & Açúcar & Café & Soma \\
\hline 1991 & 6,4 & 2,9 & 2,6 & 1,2 & 1,3 & 1,4 & 4,8 & 20,6 \\
1992 & 7,5 & 3,0 & 2,7 & 1,2 & 1,6 & 1,7 & 3,2 & 20,9 \\
1993 & 8,0 & 2,2 & 2,3 & 1,5 & 1,6 & 2,0 & 3,4 & 20,9 \\
1994 & 9,5 & 2,3 & 2,3 & 1,4 & 1,3 & 2,3 & 5,9 & 25,1 \\
1995 & 8,2 & 2,4 & 2,5 & 1,4 & 1,1 & 4,1 & 5,3 & 25,0 \\
1996 & 9,3 & 3,0 & 3,2 & 1,8 & 0,9 & 3,4 & 4,5 & 26,0 \\
1997 & 10,8 & 1,9 & 3,1 & 1,7 & 0,8 & 3,3 & 5,9 & 27,6 \\
1998 & 9,3 & 2,5 & 3,0 & 1,4 & 1,1 & 3,8 & 5,1 & 26,4 \\
1999 & 7,9 & 2,6 & 2,0 & 1,8 & 1,6 & 4,0 & 5,1 & 25,1 \\
2000 & 7,6 & 1,9 & 1,5 & 1,5 & 1,4 & 2,2 & 3,2 & 19,4 \\
2001 & 9,1 & 1,5 & 1,6 & 2,2 & 1,8 & 3,9 & 2,4 & 22,5 \\
\hline
\end{tabular}

Fonte: Sistema ALICE. Cálculos efetuados pelos autores.

A participação das exportações brasileiras no mercado internacional apresentou comportamento diferenciado entre os produtos aqui considerados. As exportações de soja e derivados, frango, carne bovina e açúcar apresentaram tendência de crescimento da parcela brasileira sobre o total mundial, ao longo da década de 1990. No entanto, o suco de laranja, fumo e café apresentaram comportamento estável ou até mesmo diminuíram sua participação nas exportações mundiais no período, conforme apresentado na Tabela 2.

As informações sobre a participação brasileira nas exportações agrícolas mundiais reforçam a importância desses produtos para o cenário internacional e revelam a capacidade de reorganização desses setores ao longo da referida década. Nesse sentido, mesmo com a manutenção de posições protecionistas por parte dos países desenvolvidos, a participação das exportações agrícolas brasileiras, em geral, tem aumentado. A cadeia da soja, por exemplo, obteve, ao longo dessa década, elevados ganhos de produtividade, estimulados por mudanças nos preços relativos, pelo crescimento de mercados consumidores (como o asiático) e 
pelo desenvolvimento e adoção de novas tecnologias. Como resultado desse desempenho, o Brasil tornou-se o maior exportador de soja do mundo.

Tabela 02 - Participação brasileira nas exportações agrícolas mundiais (\%), 1991-2001

\begin{tabular}{lccccccc}
\hline Ano & $\begin{array}{c}\text { Soja e } \\
\text { derivados }\end{array}$ & $\begin{array}{c}\text { Suco de } \\
\text { laranja }\end{array}$ & Fumo & Frango & $\begin{array}{c}\text { Carne } \\
\text { Bovina }\end{array}$ & Açúcar & Café \\
\hline 1991 & 15,7 & 25,8 & 4,2 & 10,9 & 2,6 & 4,3 & 18,0 \\
1992 & 19,0 & 27,8 & 4,5 & 11,0 & 3,5 & 6,0 & 15,4 \\
1993 & 21,3 & 23,6 & 4,6 & 13,4 & 3,8 & 8,8 & 16,6 \\
1994 & 25,6 & 24,0 & 4,7 & 11,5 & 3,4 & 9,8 & 19,2 \\
1995 & 22,2 & 23,0 & 5,2 & 10,1 & 2,8 & 14,6 & 15,6 \\
1996 & 21,6 & 26,3 & 5,8 & 11,3 & 3,0 & 12,4 & 15,4 \\
1997 & 23,5 & 22,4 & 6,4 & 12,7 & 2,9 & 14,2 & 18,5 \\
1998 & 22,6 & 24,6 & 6,3 & 10,8 & 4,1 & 16,0 & 16,6 \\
1999 & 21,6 & 24,4 & 4,4 & 13,4 & 5,0 & 19,0 & 18,8 \\
2000 & 22,5 & 22,3 & 3,8 & 12,6 & 5,1 & 13,5 & 15,4 \\
2001 & 24,9 & 19,9 & 4,6 & 17,1 & 7,5 & 21,7 & 16,2 \\
\hline
\end{tabular}

Fonte: Sistema ALICE, FAO. Cálculos efetuados pelos autores.

No caso específico dos produtos de origem animal, como a carne bovina e o frango, o Brasil vem ocupando maior espaço no cenário internacional, também em razão de aspectos sanitários, como o surgimento de focos de Encefalopatia Espongiforme Bovina (EEB ou, em inglês, BSE, popularmente conhecida como o "mal-da-vaca-louca") e, mais recentemente, de Influenza Aviária (popularmente conhecida como a "gripe-dofrango"), que resultaram na abertura de novos mercados para os produtos brasileiros. Outro aspecto que também favoreceu a expansão das exportações brasileiras foi, a partir de janeiro de 1999, o processo de desvalorização do real, tornando os produtos brasileiros mais competitivos no mercado internacional. 
Analisando as exportações agrícolas por destino, ainda que o extremo oriente esteja expandindo suas compras no mercado internacional (e o Brasil tem-se beneficiado cada vez mais dessa situação), observou-se que a UE é um dos principais mercados de destino das exportações brasileiras. Nesse sentido, verificou-se que a maior parte das exportações brasileiras de soja e derivados, suco de laranja, fumo, carne bovina e café é exportada para a UE, de acordo com os dados apresentados na Tabela 3.

Quando comparados os resultados globais de comércio com a UE, temse que as exportações totais brasileiras para a UE atingiram, em 2001, US\$ 14,9 bilhões, o que corresponde a $25,5 \%$ do total de exportações brasileiras (US\$ 58,2 bilhões). Mas, quando são considerados apenas os sete agregados de produtos agrícolas, verifica-se que as exportações brasileiras para a UE alcançaram, naquele mesmo ano, US\$ 6,0 bilhões, o que corresponde a $45,9 \%$ do total das exportações brasileiras desses produtos (realçando a importância da UE como destino das exportações agrícolas brasileiras) e 40,5\% do total das exportações nacionais para a UE (realçando a importância dos produtos agrícolas na pauta exportadora brasileira para a UE).

Tabela 03 - Participação da UE no destino das principais exportações agrícolas brasileiras, 1991-2001

\begin{tabular}{c|ccccccc}
\hline Ano & $\begin{array}{c}\text { Soja e } \\
\text { derivados }\end{array}$ & $\begin{array}{c}\text { Suco de } \\
\text { laranja }\end{array}$ & Fumo & Frango & $\begin{array}{c}\text { Carne } \\
\text { Bovina }\end{array}$ & Açúcar & Café \\
\hline 1991 & 73,6 & 53,0 & 55,5 & 10,9 & 75,9 & 1,1 & 49,2 \\
1992 & 71,8 & 53,8 & 53,9 & 15,2 & 72,4 & 1,7 & 49,0 \\
1993 & 68,4 & 58,0 & 47,9 & 12,4 & 63,6 & 4,7 & 47,5 \\
1994 & 68,2 & 56,5 & 50,9 & 16,7 & 66,0 & 5,0 & 47,4 \\
1995 & 61,9 & 72,7 & 50,2 & 12,6 & 70,3 & 1,5 & 43,1 \\
1996 & 60,5 & 66,7 & 43,9 & 17,0 & 70,0 & 1,2 & 44,5 \\
1997 & 64,6 & 67,2 & 39,7 & 18,3 & 67,1 & 1,8 & 52,2 \\
1998 & 59,2 & 73,2 & 39,3 & 16,6 & 61,7 & 1,8 & 50,6 \\
1999 & 62,8 & 71,7 & 46,1 & 16,7 & 61,2 & 1,1 & 50,8 \\
2000 & 64,2 & 66,7 & 37,1 & 23,6 & 59,7 & 0,8 & 51,0 \\
2001 & 64,2 & 70,3 & 38,0 & 32,4 & 45,3 & 0,7 & 52,6 \\
\hline
\end{tabular}

Fonte: Sistema ALICE. Cálculos efetuados pelos autores. 
Convém, ainda, observar que, ao longo da última década, houve aumento da participação da UE no destino das exportações brasileiras de suco de laranja e frango, mas redução no caso da soja e derivados, fumo e carne bovina. O café e o açúcar apresentaram comportamentos estáveis, sendo a participação da EU, como destino das exportações brasileiras de açúcar, irrisória, dado o protecionismo que o bloco impõe ao segmento.

Com vistas a analisar os efeitos das mudanças políticas e econômicas que ocorreram ao longo da década de 1990 aqui foi retratado, em termos de participação de mercado, o comportamento de produtos selecionados na pauta de exportação brasileira e no mercado internacional. Contudo, a análise pode ser aprofundada se avalia a eficiência produtiva e comercial das cadeias agroindustriais a partir do cálculo dos índices de Vantagens Comparativas Reveladas e de Orientação Regional, conforme descrito na seção a seguir, permitindo entender melhor as implicações do acordo interblocos entre Mercosul e UE, nos segmentos aqui analisados.

\section{Metodologia}

Yeats (1997) enfatizou que a recente proliferação de acordos regionais traz algumas preocupações. Citou, em primeiro lugar, o receio de que os acordos regionais possam desviar a atenção do processo de negociação multilateral, iniciado no âmbito do GATT e seguido pela OMC, para reduzir as barreiras ao comércio internacional. Além disso, há preocupação com o fato de que alguns acordos regionais possam criar barreiras contra países não-membros, gerando efeitos indesejáveis, como o desvio de comércio, que é expresso pela substituição dos fluxos comerciais de países mais eficientes por fluxos de países membros beneficiados por um tratamento preferencial. Dadas essas preocupações, Yeats (1997) propôs o cálculo de índices para medir a eficiência produtiva no contexto de transformações nos padrões de comércio, verificando os efeitos dos acordos regionais. Sugeriu a utilização, em conjunto, de dois índices que medem as Vantagens Comparativas Reveladas e a Orientação Regional das exportações, trazendo informações a respeito dos efeitos dos acor- 
dos sobre os fluxos comerciais na região. Naquele artigo, o autor, ao analisar o desempenho comercial no Mercosul, indicou que os produtos que apresentam o maior crescimento no comércio intrabloco no Mercosul, geralmente, são produtos para os quais os países membros não têm vantagens comparativas, o que é consistente com o conceito de desvio de comércio.

Neste artigo, propôs-se a utilização dos índices para verificar se existem, ou não, vantagens comparativas e identificar a orientação das exportações agrícolas brasileiras em direção à UE e a possibilidade de criação ou desvio de comércio mediante um acordo entre os blocos. $\mathrm{O}$ índice que reflete as Vantagens Comparativas Reveladas $(C j)$ pode ser calculado para cada produto comercializado e para cada país participante dos acordos regionais. Esse índice é definido por:

$$
C_{j}=\left(X_{i j} / X_{i}\right) /\left(X_{w j} / X_{w}\right)
$$

em que $X_{i j}=$ valor das exportações do produto $j$ pelo país $i$;

$X_{i}=$ valor das exportações totais pelo país $i$;

$X_{w j}=$ valor das exportações mundiais do produto $j$; e

$X_{w}=$ valor das exportações mundiais totais.

O índice $\mathrm{Cj}$ é uma razão de proporções, cujo resultado é obtido por meio da divisão da participação das exportações do produto $j$ na pauta de exportações do país $i$ pela participação das exportações do mesmo produto $j$ na pauta mundial de exportações, ou seja, seu resultado revela se determinado país (neste caso, o Brasil) possui vantagens comparativas, ao comparar seu peso dentro da pauta exportadora brasileira com a mundial. O índice $C j$ pode variar de zero a infinito. Valores acima da unidade indicam que o país tem vantagem comparativa revelada naquele produto $j$, enquanto valores abaixo da unidade indicam que o país em questão apresenta desvantagem comparativa revelada. 
No cálculo do índice, Yeats (1997) observou que os fluxos intra-regionais (considerando os acordos dos quais o país participa) podem ser excluídos, para refletir melhor a capacidade do país em competir nos mercados internacionais, sem a presença de distorções ou tratamentos preferenciais. Em geral, o índice de Vantagens Comparativas Reveladas só é calculado para produtos processados ou manufaturados, porque o comércio internacional de produtos agrícolas é bastante distorcido quando há subsídios à exportação e barreiras comerciais, que podem viesar a análise. Entretanto, nesses casos em que o Brasil tem grande participação no mercado internacional e enfrenta barreiras impostas principalmente pelos países desenvolvidos, o cálculo do índice pode subestimar as reais vantagens comparativas brasileiras.

Por sua vez, o Índice de Orientação Regional $\left(R_{j}\right)$, para as exportações do produto $j$, é definido por:

$$
R_{j}=\left(X_{r j} / X_{r t}\right) /\left(X_{o j} / X_{o t}\right)
$$

em que:

$X_{r j}=$ valor das exportações intra-regionais do produto $j$;

$X_{r t}=$ valor das exportações intra-regionais totais;

$X_{o j}=$ valor das exportações extra-regionais do produto $j$; e

$X_{o t}=$ valor das exportações extra-regionais totais.

O $R_{j}$ é também uma razão entre duas proporções, e seu resultado provém da divisão da participação das exportações de determinado produto $j$ sobre as exportações totais intra-regionais pela participação desse mesmo produto $j$ no total das exportações destinadas para fora da região considerada. No caso deste artigo, em que se analisa a orientação das exportações brasileiras para a UE, no cálculo consideram-se os valores das exportações (de cada produto j e das exportações totais) com origem no Brasil e destino nos países que compõem a UE como os valores intra-regionais, bem como os valores das exportações com origem no 
Brasil e destino nos outros países (não-membros da UE) como os valores extra-regionais. $\mathrm{O}$ índice também situa-se num intervalo de zero a infinito, no qual a unidade indica uma mesma tendência para exportar o produto a membros e a não-membros. Valores crescentes de $R_{j}$, observados ao longo do tempo, indicam tendência para exportar mais para dentro do bloco.

Alguns pontos devem ser observados no Índice de Orientação Regional. Primeiro, ele comporta apenas informação limitada sobre os padrões de comércio, se for computado num único período de tempo. Diversos fatores, como vantagens comparativas, custos de transporte ou barreiras comerciais em mercados alternativos, são determinantes da orientação geográfica dos fluxos comerciais. No entanto, comparações do índice ao longo do tempo podem ser muito úteis na análise das transformações nos padrões geográficos desses fluxos. Segundo, no curto e médio prazos, as mudanças nas vantagens comparativas, nos custos de transporte e nas preferências dos consumidores tendem a ser pequenas, de modo que aspectos como a formalização de acordos regionais e alterações nas barreiras comerciais podem influenciar esse índice mais acentuadamente. Terceiro, vistas isoladamente, variações percentuais nas exportações de diferentes produtos, dentro dos acordos regionais, não indicam variações na demanda em terceiros mercados. Por exemplo, até mesmo produtos com altas taxas de crescimento dentro do bloco podem apresentar redução na orientação regional das exportações se as exportações extra-regionais estiverem crescendo mais rapidamente. O Índice de Orientação Regional não apresenta esse problema (Yeats, 1997).

No cálculo dos índices de orientação regional e de vantagens comparativas reveladas, os dados das exportações totais brasileiras e das exportações dos produtos específicos foram obtidos do Sistema de Análise das Informações de Comércio Exterior (Sistema ALICE), da Secretaria de Comércio Exterior (SECEX), do Ministério do Desenvolvimento, Indústria e Comércio Exterior (MDIC). ALICE disponibiliza, de forma sistemática, os dados das exportações e importações brasileiras, de acordo com o destino ou origem. Neste artigo foram utilizados os dados das exportações brasileiras (Free on Board - FOB), expressos em dólares 
americanos (US\$), no período de 1991 a 2001. Como apontado anteriormente, consideraram-se as exportações de soja e derivados (grão, farelo e óleo), suco de laranja (concentrado e não-concentrado), fumo (folhas e manufaturados), frango (in natura - inteiro ou em pedaços - e industrializado), carne bovina (refrigerada, congelada e industrializada), açúcar (bruto e refinado) e café (grão, torrado e solúvel).

Os valores das exportações mundiais dos produtos foram obtidos da Food and Agriculture Organization (FAO), órgão das Nações Unidas para Agricultura e Alimentação. As bases de dados foram compatibilizadas, considerando-se a necessidade de obter a equivalência das diferentes classificações dos produtos ${ }^{7}$. Esses dados também estão expressos em US\$, no período de 1991 a 2001. Os valores das exportações intra-regionais foram obtidos da soma dos valores das exportações de cada produto $j$, para cada um dos 15 países que compunham a UE, enquanto os valores das exportações extra-regionais o foram, da diferença entre o total exportado do produto $j$ pelo Brasil para o mundo e o montante que é exportado para os países da UE. Da mesma forma, calcularam-se os valores referentes às exportações totais.

\section{Resultados}

As vantagens comparativas reveladas, apresentadas na Tabela 4, ilustram a competitividade das cadeias agroindustriais brasileiras diante dos demais países exportadores no mercado internacional. Os valores do VCR acima de 1,0 indicam vantagens comparativas favoráveis aos produtos brasileiros em questão. Todas as cadeias analisadas apresentaram VCR bem acima de 1,0 e, portanto, possuíam nível de eficiência na produção e na comercialização maior do que os demais países atuantes no mercado internacional, apesar das distorções nos mercados internacionais. Os agregados de produtos de maior destaque, em termos de índices mais elevados, foram soja e derivados, suco de laranja, frango, açúcar e café. Entretanto,

\footnotetext{
${ }^{7}$ No Sistema ALICE, a classificação é por códigos das mercadorias correspondentes à Nomenclatura Comum do Mercosul - NCM, enquanto na FAO por grandes agregados de produtos.
} 
aqueles que expressavam valores crescentes, ao longo do período, foram soja e derivados, frango, carne bovina e açúcar, os quais caracterizavam uma tendência de aumento na competitividade global ao longo da década de 1990. Tal comportamento se explica pelo maior crescimento das exportações desses produtos e diante dos demais produtos exportados pelo país, relativamente ao crescimento das exportações mundiais.

Tabela 04 - Índice de Vantagens Comparativas Reveladas (VCR) das principais exportações agrícolas brasileiras, 1991-2001

\begin{tabular}{c|ccccccc}
\hline Ano & $\begin{array}{c}\text { Soja e } \\
\text { derivados }\end{array}$ & $\begin{array}{c}\text { Suco de } \\
\text { laranja }\end{array}$ & Fumo & Frango & $\begin{array}{c}\text { Carne } \\
\text { Bovina }\end{array}$ & Açúcar & Café \\
\hline 1991 & 17,44 & 28,63 & 4,63 & 12,14 & 2,93 & 4,81 & 20,05 \\
1992 & 20,01 & 29,21 & 4,73 & 11,53 & 3,65 & 6,35 & 16,24 \\
1993 & 20,84 & 23,16 & 4,48 & 13,14 & 3,76 & 8,61 & 16,27 \\
1994 & 25,41 & 23,88 & 4,70 & 11,45 & 3,39 & 9,69 & 19,04 \\
1995 & 24,58 & 25,52 & 5,75 & 11,15 & 3,13 & 16,17 & 17,31 \\
1996 & 24,38 & 29,64 & 6,59 & 12,74 & 3,41 & 14,04 & 17,38 \\
1997 & 24,78 & 23,58 & 6,68 & 13,40 & 3,07 & 14,94 & 19,42 \\
1998 & 24,25 & 26,47 & 6,81 & 11,55 & 4,36 & 17,18 & 17,85 \\
1999 & 25,66 & 29,01 & 5,18 & 15,97 & 5,96 & 22,62 & 22,29 \\
2000 & 26,24 & 26,07 & 4,41 & 14,72 & 5,97 & 15,77 & 17,96 \\
2001 & 26,45 & 21,11 & 4,84 & 18,14 & 7,96 & 23,04 & 17,18 \\
\hline
\end{tabular}

Fonte: Sistema ALICE, FAO. Cálculos efetuados pelos autores.

O índice VCR da soja e derivados, frango, carne bovina e açúcar cresceu, respectivamente, 51,$7 ; 49,4 ; 171,7$; e 379,0\% no período de 1991 a 2001. As cadeias agroindustriais do suco de laranja e café, apesar de terem participação importante no mercado internacional, apresentaram redução desse índice, o que indica queda no grau de competitividade no mercado internacional, mas ainda mantiveram vantagens comparativas com relação aos demais países exportadores. Nesse sentido, a cadeia do suco de laranja e do café tiveram os seus VCRs reduzidos em 26,3 e $14,3 \%$, respectivamente, ao longo daquela década. Essas mudanças de posições nas cadeias analisadas podem estar relacionadas com o com- 
portamento da eficiência produtiva ao longo dos anos de 1990, mas também com a existência de diferentes barreiras tarifárias e não-tarifárias aplicadas por terceiros países. De maneira geral, o acordo comercial no âmbito multilateral permitiu pequenos acréscimos no comércio entre os países, ao longo desse período, à medida que os países desenvolvidos pouco fizeram em termos de abertura dos seus mercados e da redução dos subsídios concedidos à produção agrícola. No entanto, nos países do Mercosul houve significativa abertura comercial, estabilização econômica e maior desenvolvimento tecnológico, focados na ampliação da eficiência produtiva nos diversos segmentos da cadeia agroindustrial, fatores que permitiram ampliar a competitividade das exportações agrícolas no mercado internacional.

Esses resultados podem ser comparados com os de Barbosa e Waquil (2001), que analisaram o VCR e o IOR das exportações de soja e derivados, suco de laranja, fumo, frango, açúcar e café, no período de 1989 a 1999, considerando-se como destino das exportações brasileiras os países participantes das negociações para formação da Área de Livre Comércio das Américas (ALCA). Com relação ao VCR, os resultados de Barbosa e Waquil são semelhantes aos apresentados na Tabela 4, seguindo-se as mesmas tendências e confirmando a ocorrência de vantagens comparativas reveladas das exportações agrícolas brasileiras. Ao contrário do VCR, que indica qual o peso das exportações brasileiras na pauta mundial, o IOR sinalizou a capacidade do país de inserção dos seus produtos numa região específica. No caso presente, valores do IOR acima de 1,0 indicam maior orientação das exportações brasileiras de cada produto aqui considerado para a UE. Nesse sentido, de acordo com os resultados da Tabela 5, com exceção do frango e do açúcar, todas as demais exportações agrícolas apresentaram IOR maiores do que 1,0 e, portanto, tiveram maior orientação para a UE.

Pôde-se observar, também, que o IOR exibiu diferentes comportamentos ao longo do período analisado, conforme o produto considerado. A soja e derivados, fumo e café tiveram desempenho estável, mantendo a orientação das exportações destinadas à UE. No caso da soja e deriva- 
dos, o IOR se manteve, apesar do aumento do VCR, o que indica que tal incremento nas vantagens comparativas influencia, de forma mais ou menos equilibrada, os diversos mercados atendidos. Assim, dados o aumento das vantagens comparativas e a maior inserção nos mercados internacionais, as exportações de soja cresceram mais ou menos proporcionalmente no mercado europeu e nos outros mercados atendidos, praticamente mantendo a orientação regional.

O suco de laranja foi o único produto que apresentou aumento no IOR ao longo do período, o que caracteriza maior orientação das exportações para a UE. Esse aumento do IOR deu-se mesmo com uma sensível redução no VCR (mas que se mantém acima de 1,0). Assim, as exportações brasileiras, apesar de perderem vantagens comparativas no mercado internacional, foram reorientadas, ocupando maior espaço no mercado europeu. A carne bovina apresentou comportamento oposto ao do suco de laranja, pois teve redução no IOR nesse período, que ocorreu paralelamente a um aumento no VCR. Esse comportamento das exportações de carne bovina indicou que também houve uma reorientação, mas agora em direção a outros mercados, conquistados em decorrência dos ganhos de vantagens comparativas.

Tabela 5 - Índice de Orientação Regional (IOR) das principais exportações agrícolas brasileiras, 1991-2001

\begin{tabular}{c|ccccccc}
\hline Ano & $\begin{array}{c}\text { Soja e } \\
\text { derivados }\end{array}$ & $\begin{array}{c}\text { Suco de } \\
\text { laranja }\end{array}$ & Fumo & Frango & $\begin{array}{c}\text { Carne } \\
\text { Bovina }\end{array}$ & Açúcar & Café \\
\hline 1991 & 5,95 & 2,40 & 2,66 & 0,26 & 6,72 & 0,02 & 2,06 \\
1992 & 5,91 & 2,71 & 2,72 & 0,42 & 6,09 & 0,04 & 2,23 \\
1993 & 6,04 & 3,84 & 2,55 & 0,39 & 4,87 & 0,14 & 2,52 \\
1994 & 5,52 & 3,34 & 2,67 & 0,51 & 5,00 & 0,14 & 2,32 \\
1995 & 4,22 & 6,92 & 2,62 & 0,38 & 6,15 & 0,04 & 1,97 \\
1996 & 4,16 & 5,45 & 2,13 & 0,56 & 6,35 & 0,03 & 2,18 \\
1997 & 4,85 & 5,44 & 1,74 & 0,59 & 5,41 & 0,05 & 2,90 \\
1998 & 3,57 & 6,73 & 1,60 & 0,49 & 3,98 & 0,05 & 2,53 \\
1999 & 4,22 & 6,33 & 2,14 & 0,50 & 3,93 & 0,03 & 2,58 \\
2000 & 4,89 & 5,46 & 1,60 & 0,84 & 4,04 & 0,02 & 2,84 \\
2001 & 5,24 & 6,92 & 1,79 & 1,40 & 2,42 & 0,02 & 3,23 \\
\hline
\end{tabular}

Fonte: Sistema ALICE, FAO. Cálculos efetuados pelos autores. 
No caso do frango e do açúcar, o IOR abaixo da unidade ilustra uma pequena orientação das exportações brasileiras para a UE. Entretanto, ambos os produtos tiveram VCR elevado e crescente ao longo do período. Com isso, apesar de o país apresentar maiores vantagens comparativas, ele não consegue orientar suas exportações para aquele bloco, em vista das barreiras impostas sobre os produtos brasileiros. Essa situação é mais acentuada no caso do açúcar, cujo IOR se manteve sempre muito próximo de zero. No caso do frango, o IOR elevou-se ao longo do período, chegando, em 2001, a superar a unidade, evidenciando uma reorientação das exportações e a ocupação de um espaço maior no mercado europeu.

Em termos percentuais, as maiores variações positivas do IOR ao longo do período ocorreram nos casos do frango (438,5\%), do suco de laranja $(188,3 \%)$ e do café $(56,8 \%)$. No entanto, a maior variação negativa aconteceu para a carne bovina, que chegou a alcançar $-64,0 \%$.

Já, no trabalho de Barbosa e Waquil (2001), no cálculo do IOR considerou-se o destino das exportações brasileiras para os países da ALCA. Nesse cenário, os autores obtiveram, para soja e derivados, suco de laranja, fumo, açúcar e café, valores de IOR abaixo de 1,0. No caso do frango, esses valores chegaram a ser menores do que 0,1 , o que revela uma pequena capacidade de exportação agrícola brasileira para aquela região. Os resultados obtidos por esses autores indicaram que o peso das exportações extra-Alca é maior do que das exportações intra-Alca. Comparando os resultados de Barbosa e Waquil com os apresentados neste artigo, pode-se inferir que o país apresentou vantagens comparativas reveladas nas exportações agrícolas, mas houve maior orientação dessas exportações agrícolas brasileiras para os países da EU, do que para os países da ALCA.

Em suma, ambos os índices permitem analisar a capacidade das cadeias estudadas em redirecionar ou ampliar as exportações agrícolas brasileiras para a UE, no caso da formação do acordo entre os países do Mercosul e da UE. Apesar das elevadas vantagens comparativas, alguns produtos ainda apresentaram pequena orientação regional, tendendo a aumentar 
mediante a eliminação (ou ao menos a redução) das barreiras tarifárias e não-tarifárias impostas aos produtos brasileiros pela UE. O caso mais crítico, como apontado a seguir, foi o do açúcar, que apresentou uma grande diferença entre os valores de VCR e IOR, o que indica elevada eficiência na produção, mas enfrentou fortes barreiras à entrada no mercado europeu.

\section{Mecanismos de proteção da UE e barreiras aos produtos agrí- colas brasileiros}

Os principais instrumentos de proteção do mercado doméstico da UE estão associados à Política Agrícola Comum (PAC). Em termos gerais, existem as barreiras tarifárias a terceiros países (tarifas ad valorem e quotas tarifárias), mantendo o nível de preços mais elevado no mercado doméstico; os subsídios concedidos aos produtores, permitindo maior renda ao produtor, mas também responsáveis pela geração de excedentes agrícolas; e os subsídios à exportação, permitindo eliminar os excessos de oferta do mercado doméstico e tornar os produtos agrícolas europeus mais competitivos no mercado internacional. Além das barreiras tarifárias e dos subsídios, havia barreiras não-tarifárias, a exemplo, das barreiras sanitárias e fitossanitárias e as técnicas, que dificultavam a entrada de produtos que não seguem a certificação européia de qualidade, obedecendo a critérios muitas vezes subjetivos, impedindo as importações conforme os interesses dos países da UE.

Como um dos principais exemplos das práticas de protecionismo agrícola na EU, tem-se o caso do açúcar, cuja produção é viabilizada naquela região pelos instrumentos da PAC. Os principais mecanismos são o sistema de quotas de produção, quotas tarifárias e os subsídios à exportação. No sistema de quotas de produção, é estabelecido um preço de intervenção, anualmente, ao açúcar, à isoglicose e ao xarope de insulina, com o duplo objetivo de atender à demanda doméstica e incrementar a renda dos produtores. Com vistas a viabilizar esse processo, foram estabelecidas barreiras à entrada de produtos, as quais ocorria, princi- 
palmente, na forma de quotas tarifárias. Para o Brasil, a quota era de 23.930 toneladas ao ano de açúcar de cana bruto, destinado ao refino, a uma tarifa de 98 euros/tonelada; quando a quantidade excedia aquele montante, a tarifa tornava-se proibitiva (acima da quota estabelecida, a tarifa chega a atingir 339 euros/tonelada). O último instrumento consiste nos subsídios concedidos à exportação de açúcar para terceiros mercados, a fim de impedir que os preços dentro da UE diminuam nos anos em que houver excesso de oferta. Esses três mecanismos conseguem, praticamente, barrar as exportações brasileiras de açúcar para a UE, desviando-as para outras regiões (Missão, 2000).

Apesar de na UE as tarifas médias impostas aos produtos importados serem de 5,95\%, no caso do fumo elas podem alcançar 88,9\%. A importação do fumo brasileiro também estava sujeita ao sistema de quotatarifária, impondo tarifas variando de 19,9 a $88,9 \%$, dependendo da quantidade e do tipo de fumo importado pela UE. No caso do café e da soja, as tarifas eram menores do que as do fumo e do açúcar. No caso da soja e derivados, eram impostas diferentes tarifas, conforme o grau de beneficiamento do produto. Quanto ao grão, ela era de $0,0 \%$, e para o óleo de soja bruto, para uso industrial, de 3,2\% (consumo final: 6,4\%). Já o óleo refinado, para uso industrial, estava sujeito a tarifas de 5,1\% (consumo final: 9,6\%). Por fim, a escalada tarifária também se aplicava ao café, que possuía uma tarifa de $8,0 \%$ para o produto em grão não torrado descafeinado e de 9,0\% para o café solúvel (Missão, 2000). Nesses casos, a aplicação da escalada tarifária dificultava as exportações brasileiras de produtos mais processados, com maior valor agregado, induzindo o país a exportar produtos de mais baixo valor agregado.

Para a carne de frango e bovina, os principais instrumentos aplicados eram as quotas tarifárias, os subsídios à exportação e as barreiras sanitárias. Com relação às quotas tarifárias, para a carne bovina havia possibilidade de o Brasil exportar até 5 mil toneladas, a uma tarifa de $20 \%$, enquanto nas quantidades excedentes se aplicava uma tarifa de $12,8 \%$, acrescida de 304,10 euros/tonelada. Já, para a carne de frango, a quota anual era de 7,5 mil toneladas, com uma tarifa 50\% inferior à normal (frango em pedaços, 108,5\%, e frango inteiro, 31,8\%) (Jank e Jales, 
2003). Associadas às barreiras tarifárias, têm-se as barreiras nãotarifárias. Nesse caso, destaca-se a proibição da importação de carne bovina com osso. Ambos os setores podem também ser beneficiados por subsídios à exportação quando houver excedentes de produção no mercado europeu (Missão, 2000). Por fim, ao suco de laranja brasileiro foi imposta uma tarifa ad valorem de $15,2 \%$, não sendo submetido ao regime de quotas-tarifárias, tampouco a salvaguardas especiais (Jank e Jales, 2003).

A partir desse cenário apresentado e das discussões anteriores a respeito das VCR e do IOR, pode-se esperar que as cadeias que tendem a auferir maiores ganhos, mediante um acordo de livre comércio entre o Mercosul e a UE, serão justamente aquelas que possuem vantagens comparativas, mas que ainda não têm maior penetração no mercado europeu, em virtude das barreiras impostas aos produtos brasileiros, como a exemplo da cadeia do açúcar e do frango, as quais poderão ser beneficiadas pela eliminação das barreiras tarifárias e não-tarifárias, tendo como conseqüência maior orientação regional e a criação de comércio entre os blocos.

\section{Conclusões}

A avaliação do comportamento do comércio dos produtos agrícolas selecionados neste artigo, com origem no Brasil e direcionados à UE, permitiu constatar que o bloco europeu é muito relevante no total das exportações agrícolas do país. Os maiores destaques ficam para soja e derivados, suco de laranja e café. Somente o açúcar brasileiro não tem a UE como um importante comprador. No que diz respeito aos resultados das vantagens comparativas reveladas, observou-se que todos os produtos tiveram resultados favoráveis, destacando-se, principalmente, soja e derivados, suco de laranja, frango, açúcar e café. De modo geral, os resultados do VCR refletem o aumento da eficiência produtiva interna, também influenciado pelos esforços do país na busca de estabilização econômica, maior abertura comercial e conquista de novos mercados. 
Em relação à orientação regional, houve significativo direcionamento dos produtos agrícolas analisados para a União Européia. As exceções ficam por conta do frango e do açúcar, ainda que o primeiro tenha crescente orientação ao longo do período avaliado. Mesmo com resultados representativos, a redução de barreiras pela UE poderá reforçar tal orientação regional dos produtos do país para àquela região, proporcionado pelas vantagens comparativas dos produtos agrícolas brasileiros, o que implica criação de comércio entre os blocos.

Esses resultados são corroborados por De Negri e Arbache (2003), segundo as quais a formação de uma zona de livre comércio, com o fim de tarifas específicas, poderá proporcionar a elevação das exportações do Brasil para o mercado europeu no montante aproximado de US\$ 691 milhões (considerando-se a média do valor exportado de 1998 a 2000). Dessa forma, um acordo entre os blocos, diminuindo ou eliminando barreiras tarifárias e não-tarifárias, representaria uma nova dinâmica nas relações comerciais entre Mercosul e UE, podendo resultar em criação de comércio e favorecendo, principalmente, as exportações agrícolas brasileiras com destino à Europa.

\section{Referências bibliográficas}

BARBOSA, Alexandre E. e WAQUIL, Paulo D. O rumo das exportações agrícolas brasileiras frente às negociações para a formação da Área de Livre Comércio das Américas (ALCA). Indicadores Econômicos FEE, Porto Alegre, v. 29, n. 3, p. 70-85, nov. 2001.

BULMER-THOMAS, Victor. A União Européia e o Mercosul: perspectivas de um tratado de livre comércio e suas implicações sobre os Estados Unidos. In: REIS, Carlos Nelson dos (Org.). América Latina: crescimento no comércio mundial e exclusão social. Porto Alegre: Dacasa Editora/Palmarinca, 2001. p. 39-63. 
BUREAU, Jean-Christophe. The agricultural issue in EU-Mercosur integration: beyond the gridlock. In: GIORDANO, P. (ed.). An integrated approach to the European Union-Mercosur Association. Paris: Fondation Nationale des Sciences Politique, 2002. p. 325-340.

JANK, Marcos S.; JALES, Mário Q. M. A agricultura nas negociações da OMC, ALCA e UE-Mercosul: impasses e perspectivas (versão preliminar). São Paulo: ICONE, 2003. Disponível em: <http://www.iconebrasil.org.br>. Acesso em: 10 jan. 2004.

MISSÃO do Brasil junto às Comunidades Européias. Obstáculos ao acesso das exportações do Brasil ao Mercado Comunitário. 2000. Disponível em: <http://www.funcex.com.br>. Acesso em: 21 ago. 2001.

NEGRI, João A.; ARBACHE, Jorge S. O impacto de um acordo entre o Mercosul e a União Européia sobre o potencial exportador brasileiro para o mercado europeu. Brasília: IPEA, 2004. (Texto para Discussão n 990).

YEATS, Alexander. Does Mercosur's trade performance raise concerns about the effects of regional trade arrangements? Policy, Planning and Research Working Paper No. 1729, Washington: Banco Mundial, fev. 1997. 


\begin{abstract}
The paper analyses the Brazilian agricultural trade with the European Union (EU), in the context of the negotiations for a commercial agreement between Mercosur and the EU. We calculate indexes of revealed comparative advantages (RCA) and regional orientation (RO), for the period from 1991 to 2001. We selected the following products: soybeans, orange juice, tobacco, chicken meat, bovine meat, sugar and coffee. Altogether, these products corresponded to more than $20 \%$ of total Brazilian exports in that period. The products that show the highest Brazilian participation in world trade are soybeans, orange juice and coffee. Except for sugar, all the analyzed products had the EU as an important destiny for the exports. The results indicate comparative advantages for the Brazilian products, showing stable or increasing indexes along the decade. Besides, there is a high orientation of Brazilian exports to the EU, except for chicken meat and sugar, but with no increases in the period. Thus, an agreement between the blocs, reducing or eliminating tariff and non-tariff barriers, may result in a trade creation, in favor of Brazilian agricultural exports to the EU.
\end{abstract}

Key-words: regional integration, international trade, comparative advantages, agriculture. 
REVISTA DE ECONOMIA E AGRONEGÓCIO, VOL.2, No 2 